\title{
Analysis of glucocorticosteroids by atmospheric pressure chemical ionization-liquid chromatography mass spectrometry (APCI-LC/MS/MS)
}

\author{
Madhusudhana I. Reddy, Alka Beotra, Ranjith B. Lal, R. Khanduja, S. J ain, T. Kaur
}

Dope Control Centre, Sports
Authority of India, J. N. Stadium,
N ew Delhi - 110003 , India

Received: 9.3.2007

Revised: 6.5.2007

Accepted: 1.7.2007

Correspondence to: Alka Beotra

E-mail: drabeotra@rediffmail.com

\begin{abstract}
O bjective: To develop a rapid liquid chromatography / mass spectrometry / mass spectrometry (LC/MS/MS) method for testing of glucocorticosteroids, which are banned in sports by the World Anti-doping Agency from January $1^{\text {st }} 2004$.

Materials and Methods: A total of 14 glucocorticosteroids were analyzed on LC/M S/M S using an Inertsil ${ }^{\circledR}$ ODS-3 $(3.0 \mu \mathrm{m}, 50 \mathrm{~mm} \times 4.6 \mathrm{~mm}$ i.d.) C-18 column in atmospheric pressure chemical ionization mode (positive ionization) with a mobile phase consisting of ammonium acetate and acetonitrile. The analytical equipment used was Aglient 1100 H PLC and API-3200 Triple quadrupole mass spectrometer.

Results: All glucocorticosteroids could be detected within 8 minutes. The limit of detection of all glucocorticosteroids by this screening method was $1 \mathrm{ng} / \mathrm{ml}$. The recovery percentage at 25 and $50 \mathrm{ng} / \mathrm{ml}$ concentrations ranged from 54\% (Prednisone) to 144\% (M ethylprednisolone).The validated method has been used successfully for testing of 500 in-competition samples. Excretion study samples of budesonide, methyl prednisolone and prednisone were analyzed by this method and the parent drugs as well as metabolites could be detected. However, further work is in progress to combine this procedure with another LC/MS/MS procedure in the ESI mode (positive ionization) being used for few anabolic steroids and heat-labile stimulants. This would help in screening of all corticosteroids, few anabolic agents and stimulants with just one injection, thus saving time and effort.
\end{abstract}

KEY WORDS: Glucocorticosteroids, detection limit, liquid chromatography / mass spectrometry / mass spectrometry
Synthetic glucocorticosteroids are a subclass of steroids, which are analogs of cortisol with respect to their chemical and pharmacological properties. They are involved in a wide range of physiological functions such as the breakdown of protein, fat and carbohydrate and the regulation of inflammation, blood electrolyte levels and behavior. ${ }^{[1]}$ Due to their regulation of inflammation, there is a widespread perception among sportsmen that these drugs have performance-enhancing effects in sports. ${ }^{[2]}$ In light of these performance-enhancing and deleterious side effects of glucocorticosteroids, the World Anti-doping Agency (WADA) banned these drugs in sports from J anuary $1^{\text {st }} 2004^{[3]}$ except to use them via the therapeutic use exemption. ${ }^{[4]}$ These glucocorticosteroids come in a variety of forms-inhalant corticosteroids are used to prevent asthma attacks, while ointments, creams and gels are used to treat skin problems. Although these are powerful drugs in curing diseases, they may cause serious side effects when incorrectly taken. A literature survey revealed that gas chromatography
I mass spectrometry (GC/MS) is not the method of choice for detection of glucocorticosteroids. ${ }^{[6]}$ There are however, a number of reported methods using liquid chromatography / mass spectrometry / mass spectrometry (LC/MS/MS) for the detection of glucocorticosteroids in doping labs ${ }^{[7-14]}$ and also in clinical practice. ${ }^{[15]}$ But the sample extraction procedure involved in each of these methods varies depending on the extraction protocol of respective labs. The objective of the present study was to develop a rapid method by extending the existing extraction protocol in our lab so that no additional sample preparation costs are involved.

\section{Materials and Methods}

\section{Reference standards}

The reference standards of glucocorticosteroids were purchased from Sigma (St. Louis, MO, USA). The organic solvents and reagents were of high performance liquid chromatography (HPLC) grade. Acetonitrile and ethyl acetate were obtained from 
Qualigens (Worli, Mumbai, India), methanol from J. T. Baker (Phillipburg, USA), tert-Butyl Methyl Ether (TBME) from Acros Organics (New Jersey, USA), formic acid from Merck (Worli, Mumbai, India). Deionised water was obtained from a Milli Q laboratory plant (Millipore, Bedford, USA).

Sample extraction procedure

The sample extraction procedure used in this study is the same as the one being used for anabolic steroids. ${ }^{[5]} \mathrm{A}$ urine sample ( 3 or $6 \mathrm{ml}$ based on specific gravity) was passed through a prepared $\mathrm{XAD}_{2}{ }^{\circledR}$ column. Elution was performed with $2.5 \mathrm{ml}$ of methanol after rinsing the column with $1 \mathrm{ml}$ of deionised water. The extract was hydrolyzed using $\beta$-glucuronidase enzyme ( $E$. coli). Liquid-liquid extraction was done by the addition of 6 $\mathrm{ml}$ of TBME; $5 \mathrm{~mL}$ of this layer was taken in a separate tube, dried under nitrogen at $60^{\circ} \mathrm{C}$, derivatized and injected into the $\mathrm{GC} / \mathrm{MS}$ for analysis of anabolic steroids. The remaining $1 \mathrm{ml}$ of the organic layer was separated and evaporated to dryness. The dried extract was reconstituted in $60 \mu \mathrm{l}$ of ammonium acetate / acetonitrile (70:30, v/v) and $10 \mu \mathrm{L}$ of this reconstituted sample was injected into the LC/MS/MS for the detection of glucocorticosteroids.

\section{Instrumentation and conditions}

The chromatographic system consisted of an Aglient 1100 series (Aglient Technologies, Waldron, Germany) equipped with a G1311A high-pressure gradient pumping system, G1329A autosampler, G1379A degasser and G1316A column compartment. An Inertsil ${ }^{\circledR} \mathrm{C}$-18 column octadecyl silyl (ODS)$3(3.0 \mu \mathrm{m}, 50 \mathrm{~mm} \times 4.6 \mathrm{~mm}$ internal diameter) (GL Sciences Inc, Tokyo, Japan) was used. The mobile phase composition was a mixture of ammonium acetate buffer / Acetonitrile (pH adjusted to 3.5 with acetic acid). It was pumped at a flow rate of $0.8 \mathrm{ml} / \mathrm{min}$ with the proportion of acetonitrile increasing from 10 to $100 \%$ in 8 minutes. Mass spectrometric analyses were conducted using an API 3200 Triple quadrupole instrument (Applied-Biosystem-Sciex, Concord, Canada) equipped with a pneumatically assisted $\mathrm{APCl}$ (heated nebulizer) ionization source. The main working parameters of the mass spectrometer are summarized in Table 1. The whole system was controlled using Analyst $1.4{ }^{\circledR}$ software (Applied-Biosystem-Sciex, Concord, Canada).

\section{Method development}

Ionization in the heated nebulizer source was performed in positive mode, scanning masses from $\mathrm{m} / \mathrm{z} 100$ to 500 with a $0.2 \mu$ step size. The development of the analytical method

\section{Table 1}

Tandem mass spectrometer working parameters

\begin{tabular}{ll}
\hline Parameter & Value \\
\hline Scan type & Multiple reaction monitoring \\
Polarity & Positive \\
lon source & Heated nebulizer \\
Nebulising gas & 3 \\
Curtain gas & 10 \\
Collision gas & 3 \\
Source temperature & $550^{\circ} \mathrm{C}$ \\
Dwell time & $60 \mathrm{msec}$ \\
\hline
\end{tabular}

was initiated with different mobile phases to achieve better separation, short run time and maximum resolution with a low flow rate. The elution of all glucocorticosteroids was between 4.98 to 6.84 minutes and of the internal standard was at 7.01 minutes. Mobile phase was introduced into the mass spectrometer via the APCl source operating in the positive ion mode under multiple reaction monitoring conditions (MRM). Nitrogen was used as a nebulizing and curtain gas to achieve fragmentation. The dwell time for each transition was $60 \mathrm{msec}$ and the interchannel delay was $5 \mathrm{msec}$. For maximum sensitivity, the mass spectrometer parameters such as nebulising gas, curtain gas and collision gas were optimized. The temperature was $550^{\circ} \mathrm{C}$ and resolution was set at the unit.

\section{Results}

\section{Method validation}

\section{Limit of detection}

To measure the limit of detection for glucocorticosteroids, a negative urine sample was spiked with $1 \mathrm{ng} / \mathrm{mL}$ of the glucocorticosteroid. Six aliquots of the control and negative urine were extracted and analyzed for a time period that covered different degrees of performance for the instrumentation. Three times the standard deviation of noise in the negative urine was used to estimate the limit of detection. Table 2 shows ions with positive ionization, collision energy and relative retention time of different glucocorticosteroids. The total ion chromatogram of glucocorticosteroids is presented in Figure 1.

\section{Calibration and quality control samples}

Working solutions for calibration and quality control samples were prepared from the stock solution by dilution using methanol. The internal standard (17 $\alpha$-Methyl testosterone) solution $(500 \mathrm{ng} / \mathrm{mL}$ ) was prepared by diluting its stock solution with methanol. Calibration standards were prepared by addition of ten micolitres of working solution to drug free urine (DFU) to obtain concentration levels of $10,25,50,100$ and $300 \mathrm{ng} / \mathrm{mL}$. Quality control samples were prepared at concentrations of 30 $\mathrm{ng} / \mathrm{mL}$ for determination of minimum required performance limit (MRPL) required by WADA, $1 \mathrm{ng} / \mathrm{mL}$ for Limit of detection (LOD) and $10 \mathrm{ng} / \mathrm{mL}$ for lower limit of quantitation (LLOQ).

\section{Calibration curve}

A calibration curve was constructed with five concentrations ranging between $10-300 \mathrm{ng} / \mathrm{mL}(10,25,50,100,300 \mathrm{ng} / \mathrm{mL})$.

Figure 1: Total ion chromatogram of glucocorticosteroids

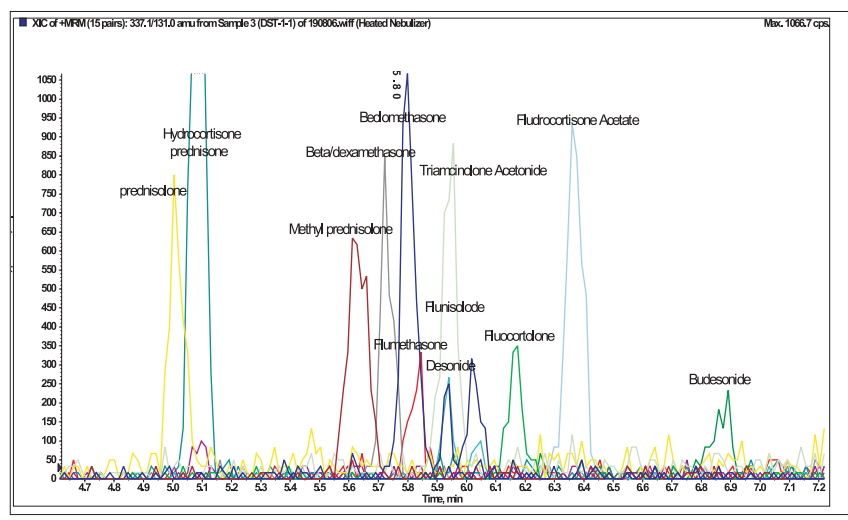


Each concentration consisted of five replicates along with an internal standard and it was injected for three consecutive days. Linearity was assessed by a weighted $(1 / x)$ least squares regression analysis method. The calibration curve had a correlation coefficient $\left(r^{2}\right)$ of 0.9999 [Figure 2]. The acceptance criterion for each calculated standard concentration was $15 \%$ deviation from the nominal value. Table 3 summarizes accuracy and precision of calculated concentrations of spiked samples of glucocorticosteroids in human urine.

\section{Specificity and matrix effect}

The specificity and matrix effect of the method was examined by analyzing the drug-free urine extract and drug-free urine spiked with the internal standard. Endogenous corticosteroid, hydrocortisone was observed with a specific peak at $5.03 \mathrm{~min}$ retention time. Ion suppression effect was observed, at the specific retention times of the analytes. In order to remove this effect, the flow rate was optimized where the retention time of the particular eluting analyte was changed. No other significant interferences were observed with the MRM channels of the analyte.
Precision and accuracy

The within-batch precision and accuracy were determined by analyzing six sets of quality control samples in a batch. The between-batch precision and accuracy were determined by analyzing six sets of quality control samples in three different batches. The quality control samples were randomized daily, processed and analyzed in position at the end of the batch. The acceptance criteria of within and between-batch precision were $20 \%$ and $15 \%$ respectively or better for the rest of concentrations. The accuracy value is within $15 \%$ of the actual value except at LLOQ, where it is not deviated by more than $20 \%$. The precision of the method was expressed as relative standard deviation and accuracy of the method was expressed in terms of bias (percentage deviation from true value).

\section{Recovery}

Recovery of glucocorticosteroids and internal standard was evaluated by comparing the mean peak areas of three processed samples (spiked) with the mean peak areas of unprocessed direct reference standard solutions of the same concentrations. Recovery of all compounds was within the limits. Internal

\section{Table 2}

lons with positive ionization, collision energy and relative retention times of different glucocorticosteroids

\begin{tabular}{|c|c|c|c|c|}
\hline Compounds & Molecular weight & lons with +ve ionization $(\mathrm{m} / \mathrm{z})$ & Collision energy & $\begin{array}{l}\text { Relative retention time } \\
\text { (min) }\end{array}$ \\
\hline Prednisolone & 361 & $361,343,147,307$ & 30 & 0.710 \\
\hline Hydrocortisone & 363 & 363,121 & 31 & 0.717 \\
\hline Prednisone & 359 & $359,147,341,171$ & 25 & 0.716 \\
\hline Methyl prednisolone & 375 & $375,161,357,339$ & 30 & 0.774 \\
\hline Beta / dexamethasone & 393 & $393,147,355,373$ & 30 & 0.820 \\
\hline Flumethasone & 411 & $411,253,121,235,335$ & 26 & 0.810 \\
\hline Beclomethasone & 409 & $409,147,279,391,373$ & 30 & 0.823 \\
\hline Triamcinolone acetonide & 435 & $435,213,397,415,121$ & 27 & 0.835 \\
\hline Desonide & 417 & $417,399,147,341,323$ & 27 & 0.835 \\
\hline Flunisolide & 435 & $435,321,121,339,171$ & 25 & 0.850 \\
\hline Flucortolone & 377 & $377,171,303,339$ & 22 & 0.868 \\
\hline Fludrocortisone acetate & 423 & $423,239,181,105$ & 45 & 0.894 \\
\hline Budesonide & 431 & $431,173,323,413$ & 33 & 0.975 \\
\hline
\end{tabular}

Table 3

Precision and accuracy data of calculated concentrations of spiked samples of glucocorticosteroids in human urine

\begin{tabular}{|c|c|c|c|c|}
\hline Compounds & Concentration added $(\mathrm{ng} / \mathrm{mL})$ & $\begin{array}{l}\text { Concentration found }(\mathrm{ng} / \mathrm{mL}) \\
\qquad \text { Mean } \pm S E\end{array}$ & $\mathrm{CV} \%$ & Accuracy \\
\hline Prednisolone & 100 & $100 \pm 5.7$ & 7.5 & 100 \\
\hline Prednisone & 100 & $105 \pm 5.7$ & 7.2 & 105 \\
\hline Methylprednisolone & 100 & $91 \pm 3.8$ & 7.1 & 91 \\
\hline Betamethasone & 100 & $99 \pm 5.5$ & 9.5 & 99 \\
\hline Flumethasone & 100 & $83 \pm 1.8$ & 3.7 & 83 \\
\hline Beclomethasone & 100 & $90 \pm 1.7$ & 3.2 & 90 \\
\hline Triamcinolone acetonide & 100 & $87 \pm 1.2$ & 2.4 & 87 \\
\hline Desonide & 100 & $93 \pm 4.2$ & 7.8 & 93 \\
\hline Flucortolone & 100 & $100 \pm 7.6$ & 13 & 100 \\
\hline Fludrocortisone acetate & 100 & $96 \pm 0.7$ & 2.6 & 96 \\
\hline Budesonide & 100 & $90 \pm 0.8$ & 1.4 & 90 \\
\hline
\end{tabular}


Figure 2: Typical calibration curve of one drug

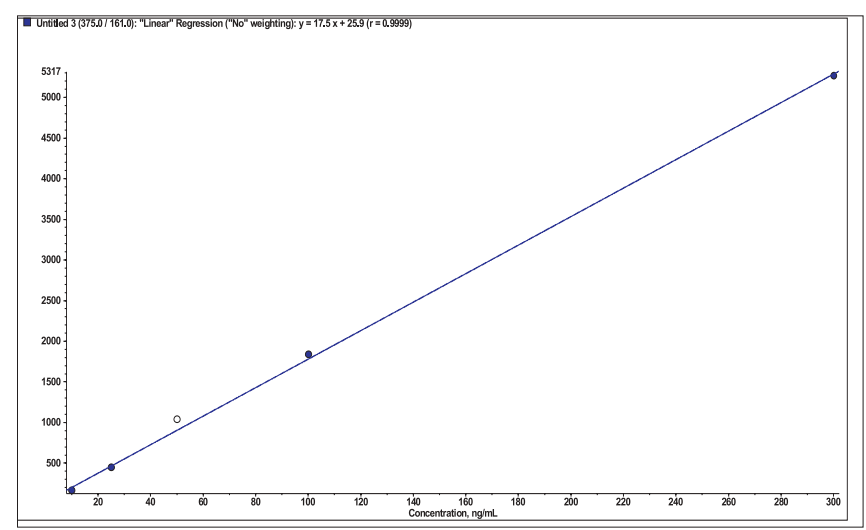

Table 4

Percent recovery of glucocorticosteroids in spiked samples of human urine

\begin{tabular}{lcc}
\hline & \multicolumn{2}{c}{ \% Recovery } \\
\cline { 2 - 3 } Compounds & $\mathbf{2 5} \mathbf{n g} / \mathbf{m l}$ & $\mathbf{5 0} \mathbf{~ g / m I}$ \\
\hline Prednisolone & 137 & 90 \\
Prednisone & $\mathrm{NA}$ & 54 \\
Methylprednisolone & 61 & 144 \\
Betamethasone / dexamethasone & 112 & 101 \\
Flumethasone & 94 & $\mathrm{NA}$ \\
Fluoxymestrone & 122 & 125 \\
Beclomethasone & 59 & $\mathrm{NA}$ \\
Triamcinolone acetonide & 139 & $\mathrm{NA}$ \\
Desonide & 83 & 130 \\
Flucortolone & $\mathrm{NA}$ & 81 \\
Fludrocortisone acetate & 122 & 112 \\
Budesonide & 112 & 141 \\
\hline
\end{tabular}

standard was acceptable as it was consistent, precise and reproducible. The range of extraction recovery varied from 54 to $144 \%$ [Table 4].

Excretion study sample

Excretion study samples of methylprednisolone, prednisone and methylprednisone were analyzed by this method and parent drug with metabolites could be detected [Figures 3-5].

\section{Discussion}

The objective of detecting and analyzing glucocorticosteroids by the existing screening protocol was achieved. A total of 14 glucocorticosteroids could be detected at the minimum required performance limit of $30 \mathrm{ng} / \mathrm{ml}$ laid down by WADA. The recovery experiments demonstrated that the analytes spiked into urine at 25 and $50 \mathrm{ng} / \mathrm{ml}$ were recovered with efficiencies ranging from 54 to $144 \%$. However, percentage recovery of glucocorticosteroids in urine has been reported in the range of 82 to $138 .{ }^{[15]}$ Extraction recovery percentages in the range of $80-120 \%$ are considered to be acceptable by international validation protocols. ${ }^{[16]}$ The protocol for bioanalytical method validation explains that the recovery of an analyte need not be $100 \%$, but the extent of recovery of an analyte and of the internal standard should be consistent, precise and reproducible. ${ }^{[17]}$
Figure 3: Mass spectrum of methylprednisolone from human urine excretion study sample

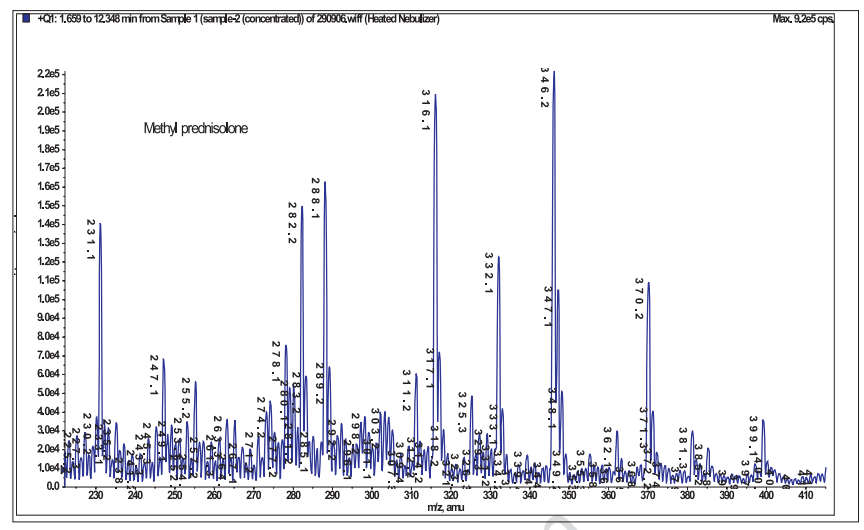

Figure 4: Mass spectrum of prednisone from human urine excretion study sample

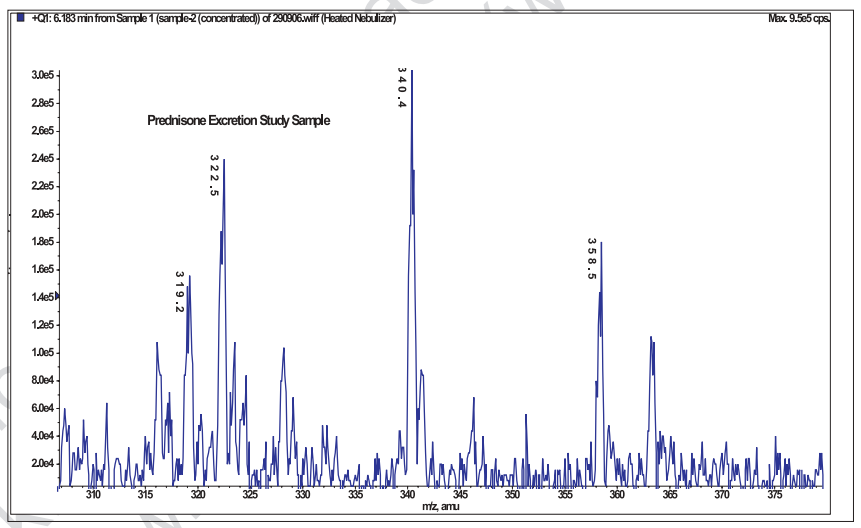

Figure 5: Mass spectrum of methylprednisone from human urine excretion study sample

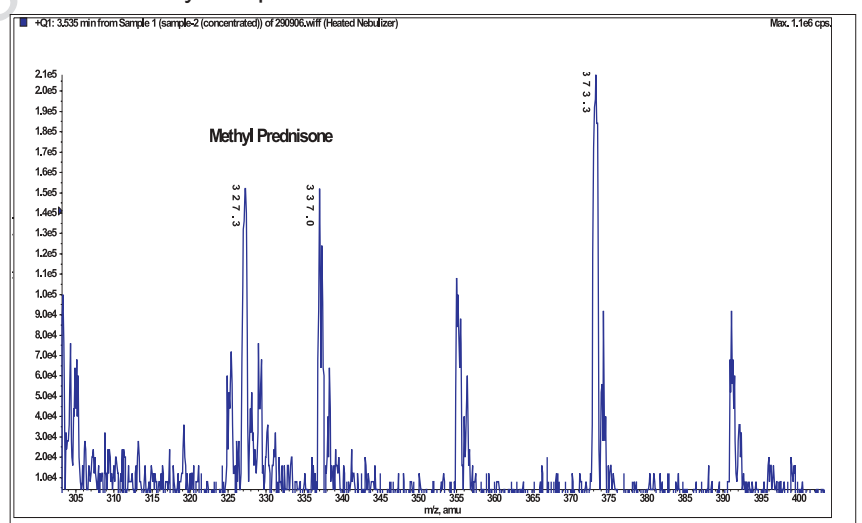

The separation of dexamethasone and betamethasone which are isomers could not be achieved by this method because both have similar MS/MS spectrum and identical retention time on a C-18 column. Another method has been developed to separate these two compounds. The validated method has been successfully used for screening and confirmation of analyte concentrations in human urine samples. However, positive 
excretion study samples of budesonide, methylprednisolone and prednisone were analyzed using this method. We could detect all the parent drugs and their metabolites by this method. The mass spectra of budesonide, methyl prednisolone and prednisone were confirmed with reference standards as per the ion match criteria of WADA. The confirmation of metabolites (16- $\alpha$ hydroxyl prednisolone, methylprednisone, prednisolone, $20 \beta$-dihydroprednisolone) was done by comparing with the reference mass spectra of metabolites as acceptable criteria laid down in WADA International Standard of Laboratories.

\section{Conclusion}

The present method could successfully detect corticosteroids as specified by WADA using the existing protocol with a detection level lower than $30 \mathrm{ng} / \mathrm{mL}$. The method can also be used successfully in clinical conditions to evaluate effects of topical and systemic synthetic corticosteroids. Further work is in progress to detect glucocorticosteroids in urine after different routes of administration.

\section{References}

1. Haynes RC Jr. In: Gilman Rall, Nies, Taylor, editors. Goodman and gilmans. The pharmacological basis of therapeutics. McGraw-Hill International Editions: New York; 1992

2. Cummiskey J. Glucocortiscosteroids in doping in sport, concerted action in the fight against doping in sport (CAF-DIS). Dublin; 2002.

3. World Anti Doping Agency, The World Anti Doping Code-The 2004 Probihited List. $1^{\text {st January-2004. }}$

4. World Anti Doping Agency, The World Anti Doping Code-Therapeutic Use Exemption-The 2005 Probihited List.

5. Jain $\mathrm{S}$, Ueki M, Ikekita A, Beotra A, Okano M. Dope testing during the $1^{\text {st }}$ afro-asian games in India. J Sports Traumatol. Allied Sports Sci 2004;5:78-89.

6. Deventer K, Delbeke FT. Validation of a screening method for corticosteroids in doping analysis by liquid chromatography/tandem mass spectrometry. Rapid Commun Mass Spectrom 2003;17:2107-14

7. Amándola L, Colamonici C, Garriba F, Botre F. Microwave-assisted derivatisation: application to the análisis of diuretics and corticosteroids. Recent advances in doping analysis (10) Sport und Buch Strauß, Koln; 2002. p. 107-15.

8. Gotzmann M, Thevis U, Mareck M. LC-MS/MS Analysis of glucocorticosteroids: First experiences with therapeutic use exemption in routine doping analysis. Recent advances in doping analysis (12) Sport und Buch Strauß, Koln; 2004. p. 55-62.

9. Goebel, Trout GJ, Kazlauskas R. Corticosteroids by LC/MS/MS-a minimalist approach. Recent advances in doping analysis (13) Sport und Buch Strauß, Koln; 2005. p. 39-46.

10. Fluri K, Rivier L, Dienes-Nagy A, You C, Maître A, Schweizer C, et al. Method for confirmation of synthetic corticosteroids in doping urine samples by liquid chromatography-electrospray ionisation mass spectrometry. J Chromatogr A 2001;926:87-95

11. Bailloux I, De Barros S, Lahaussois A, Marthurin JC, De Ceaurriz J. LCMS and LCMSMS in doping control analysis of synthetic glucocorticosteroids. Recent advances in doping analysis (8) Sport und Buch Strauß, Koln; 2000. p. 203-7.

12. Popot MA, Garcia P, Bonnaire $Y$. Screening and confirmation method for the detection of synthetic corticosteroids in human urine. Recent advances in doping analysis (5) Sport und Buch Strauß, Koln; 1997. p. 185-9.

13. Palonek $E$, Osterwall $F$, Garle M. Screening for corticosteroids in urine with online extraction and LCMSMS detection. Recent advances in doping analysis (13) Sport und Buch Strauß, Koln; 2005. p. 47-56.

14. Stolker AA, Schwillens PL, Ginkel van LA, Brinkman UA. Comparison of different liquid chromatography methods for the determination of corticosteroids in biological matrices. J Chromatography A 2000;893:55-67.

15. Robert Taylor L, Stefan Grebe K, Ravinder Singh J. Quantative, highly sensitive liquid chromatography tandem mass spectrometry method for detection of synthetic corticosteroids. Clin Chem 2004;50:2345-52.

16. De Bievre. The fitness for purpose of analytical methods. A laboratory guide to method validation and related topics. EURACHEM guidance document. October 2004.

17. Guidance for Industry-Bioanalytical method validation, U.S. Department of health and human services, FDA, CDER, CVM. May 2001.

\section{Author Help: Sending a revised article}

1) Include the referees' remarks and point to point clarification to those remarks at the beginning in the revised article file itself. In addition, mark the changes as underlined or coloured text in the article. Please include in a single file
a. referees' comments
b. point to point clarifications on the comments
c. revised article with text highlighting the changes done

2) Include the original comments of the review ers/editor with point to point reply at the beginning of the article in the 'Article File'. To ensure that the reviewer can assess the revised paper in timely fashion, please reply to the comments of the referees/editors in the following manner.

- There is no data on follow -up of these patients.

Authors' Reply: The follow up of patients have been included in the results section [Page 3, para 2]

- Authors should highlight the relation of complication to duration of diabetes.

Authors' Reply: The complications as seen in our study group has been included in the results section [Page 4, Table] 